\title{
SOSIALISASI STRATEGI PEMASARAN PADA PENGUSAHA MIKRO BOLU BHOI DI DESA LANCOK-LANCOK KABUPATEN BIREUEN
}

\author{
Saiful Hurri ${ }^{1}$, Syarifah Maihani ${ }^{2}$, Nursayuti ${ }^{3}$ \\ ${ }^{12}$ Dosen Program Studi Agribisni Fakultas Pertanian Universitas Almuslim \\ ${ }^{3}$ Dosen Program Studi Agroteknologi Fakultas Pertanian Universitas Almuslim \\ Email: saifulhurri@gmail.com, syarifahlangsa78@gmail.com,nursayuti@gmail.com
}

\begin{abstract}
ABSTRAK
Pengabdian masyarakat ini bertujuan untuk meningkatkan manajemen bisnis, pengetahuan tentang strategi pemasaran produk dan modal bisnis. Tahapan implementasi PKM, meliputi: tahap pembuatan teknologi tepat guna e-marketing, fase pelatihan yang meliputi: pelatihan manajemen bisnis (pelatihan tentang persiapan dan penyajian laporan keuangan dan pelatihan strategi pemasaran), pelatihan penggunaan $e$ commerce, permodalan, pelatihan dan simulasi manajemen membuat proposal untuk mengajukan modal dan tahap evaluasi PKM. Hasil yang dicapai yaitu telah memberikan keterampilan kepada pengusaha mikro Bolu Bhoi di Desa Lancok-Lancok Kecamatan Kuala Kabupaten Bireuen. Dari hasil pengabdian yang telah dilakukan, mitra sudah memahami tentang transaksi keuangan dan menyajikan laporan bisnis dengan rapi, benar dan berkesinambungan, meningkatkan pergantian bisnis lebih dari sebelumnya menjadi $75 \%$ dan peningkatan pengetahuan tentang modal.
\end{abstract}

Kata Kunci: $\quad$ bolu bhoi, sosialisasi strategi pemasaran, usaha mikro

\begin{abstract}
The objective of the activity is to improve business management, knowledge of strategies in product marketing and business capital.The stages of community service implementation include: creatingappropriatetechnology for e-marketing, a training phase which includes: businessmanagementtraining (training on preparation and presentation of financial reports and training on marketing strategies), training on the use of e-commerce, capital, training and proposals creation management simulation to apply for capital loan, and the evaluation stage of the community service. Results achieved: provided skills to bhoi cake maker in the village of Lancok-Lancok, Kuala District, Bireuen Regency. From the results of the community service that has been implemented, the partners have gained skillsregarding financial transactions and business reports presentation, correctly and continuously, increasing business turnover to $75 \%$ and increasing knowledge of capital.
\end{abstract}

\section{Keywords : $\quad$ bhoi cake, marketing strategy socialization, micro business}

\section{PENDAHULUAN}

Bhoi merupakan salah satu kue tradisional Aceh yang banyak diminati masyarakat, bahkan kue yang memiliki rasa khas ini semakin mendunia. Terdapat beberapa usaha Kue Bhoi di Kabupaten Bireuen, diantaranya usaha bhoi milik Rosmiani (56), usaha bhoi milik Asnidar (46), usaha bhoi milik Asriani (50), di Gampong Lancok-lancok, 
Kecamatan Kuala Kabupaten Bireuen. Usaha kue tradisional yang berdiri sejak tahun 1981, kini semakin maju dan hasil produksinya sudah dijual hingga luar daerah. Meskipun usaha mitra telah berdiri sejak lama, tetapi manajemen usaha masih bersifat kekeluargaan. Berdasarkan hasil wawancara dengan mitra, didapatkan bahwa usahanya hanya menggunakan pencatatan pesanan dan transaksi keuangan di kertas saja, pemasaran hanya dilakukan melalui brosur/flyer dan "mulut ke mulut" serta tidak memiliki pengetahuan tentang cara mendapatkan akses permodalan usaha/bank. (wawancara tanggal 15 November 2020). Kurangnya pengetahuan manajemen usaha dan strategi pemasaran usaha bhoi menyebabkan usaha mitra sulit berkembang.

Ebert., Griffin (2007), menyatakan bahwa "Manajemen sebagai sebuah proses perencanaan, pengorganisasian, pengkoordinasian dan pengontrol sumber daya untuk mencapai sasaran secara efektif dan efisien". Jadi, agar usaha dapat berjalan dengan maksimal sesuai rencana yang telah ditentukan, maka perlu diterapkan manajemen keuangan, SDM, operasional dan manajemen pemasaran. Apalagi melihat pemasaran usaha Bolu Bhoi yang masih konvensional, seharusnya telah memanfaatkan teknologi untuk menangkap permintaan Bolu Bhoi yang semakin meningkat.

Manajemen pemasaran adalah kegiatan menganalisis, merencanakan, melaksanakan, dan mengendalikan program-program yang disusun dalam pembentukan, pembangunan dan pemeliharaan keuntungan dari pertukaran/transaksi melalui sasaran pasar dengan harapan mencapai tujuan perusahaan dalam jangka panjang (Assauri, 2013). Maka, bagi Usaha Kecil dan Menengah (UKM), memanfaatkan strategi pemasaran berbasis teknologi menjadi penting dan merupakan tuntutan untuk meningkatkan daya saing.

Maju mundurnya sebuah usaha, tergantung seberapa jitu strategi pemasarannya. Salah satu strategi pemasaran adalah dengan penerapan media sosial, yang tidak hanya membantu memasarkan produk dan layanan, mengurangi biaya promosi, melengkapi merek dan melakukan komunikasi timbal balik dengan pelanggan dan pemasok tetapi berperan membantu mengidentifikasi pelanggan dari berbagi informasi untuk mengetahui objek yang disukai pelanggan, keberadaan pelanggan berdasarkan lokasi dan pola interaksi, reputasi perusahaan berkenaan dengan opini pelanggan dan 
kelompok pelanggan yang telah mapan. Beberapa strategi pemasaran yang umumnya digunakan adalah (SWOT) dan Business Model Canvas (BMC). Menurut (Ching, Hong., Fauvel, 2013) BMC memberikan wawasan bagi pengusaha dan pebisnis mengenai variasi yang berbeda yang lebih sesuai untuk bisnis mereka. Selain itu, dalam menggunakan BMC pebisnis dapat mengidentifikasi biaya yang tidak efektif dan berlebihan dalam menciptakan value bagi konsumen.

Oleh karena itu, Program Kemitraan Masyarakat (PKM) ini memberikan solusi berupa perbaikan manajemen usaha dan permodalan pada usaha Bolu Bhoi. Dari hasil kunjungan lapangan, wawancara dan pengamatan terhadap mitra, diidentifikasi beberapa permasalahan prioritas yang dihadapi mitra usaha Bolu Bhoi milik Rosmiani (56), usaha Bolu Bhoi milik Asnidar (46), usaha Bolu Bhoi milik Asriani (50), di Gampong Lancok-lancok Kecamatan Kuala Kabupaten Bireuen, yakni: 1) usaha yang dijalankan bersifat kekeluargaan dan kurangnya pengetahuan mengenai manajemen usaha yang professional; 2) kurangnya pengetahuan mengenai strategi pemasaran produk karena masih bersifat menunggu pembeli dan menyetok Bolu Bhoi; dan 3) modalnya sangat terbatas dan kurangnya akses informasi atas dana pinjaman modal/kredit bank.

Berdasarkan permasalahan prioritas yang harus ditangani, maka beberapa solusi yang ditawarkan kepada mitra adalah: a) pendampingan untuk meningkatkan manajemen usaha melalui pelatihan pembuatan dan penyajian laporan keuangan dan pelatihan strategi pemasaran; b) meningkatkan pengetahuan mengenai strategi pemasaran produk melalui e-marketing yang akan dihasilkan. Selain itu, akan dihasilkan aplikasi perhitungan stock Bolu Bhoi yang akan memudahkan untuk mengetahui jumlah stock Bolu Bhoi dan mencatat transaksi penjualan/pemesanan; dan c) meningkatkan pengetahuan mengenai permodalan usaha/kredit bank melalui pelatihan manajemen permodalan bagi usaha mikro dan simulasi pembuatan proposal pengajuan kredit bank.

Target luaran kegiatan pengabdian ini adalah: a) pendampingan manajemen usaha, Indikator keberhasilan kegiatan PKM berupa peningkatan manajemen usaha pada mitra yakni: telah diterapkannya penyajian laporan keuangan usaha yang rapi dan baik secara 
kontinyu, serta penerapan strategi pemasaran pada usaha. Terdapat kenaikan omset usaha sebesar 30\% dari kondisi sebelumnya; b) meningkatkan pengetahuan mengenai strategi pemasaran produk. Indikator keberhasilan kegiatan PKM berupa peningkatan pengetahuan mengenai strategi pemasaran produk pada mitra yakni: diterapkannya secara 100\% e-commerce dan aplikasi perhitungan stock Bolu Bhoi secara kontinyu; dan c) meningkatkan pengetahuan mengenai permodalan usaha/kredit bank. Indikator keberhasilan peningkatan pengetahuan mengenai permodalan usaha/kredit bank pada mitra yakni: pemahaman pembuatan proposal kredit bank.

\section{METODE PELAKSANAAN}

Mekanisme pelaksanaan PKM berupa rencana kegiatan yang menunjukkan langkahlangkah solusi atas persoalan mitra, berupa: 1) tahap analisis situasi dan kondisi mitra, yaitu tim pelaksana melalukan survey, pengumpulan data dan identifikasi masalah mitra, serta melakukan Focus Group Discussion (FGD) dengan mitra untuk jadwal pelaksanaan kegiatan PKM; 2) tahap pelatihan, yaitu tim pelaksana memulai kegiatan pelatihan sesuai dengan jadwal yang sudah ditentukan dan disepakati bersama dengan mitra. Adapun tahap pelatihan, meliputi: a) pelatihan manajemen usaha (pelatihan pembuatan dan penyajian laporan keuangan dan pelatihan strategi pemasaran). Pelatihan ini menggunakan modul yang dipandu oleh Syarifah Maihani, S.E., MM. (anggota PKM). Pemilik usaha diajarkan pembuatan dan penyajian laporan keuangan yang baik dan pembuatan strategi pemasaran menggunakan BMC. BMC ini adalah konsep model yang dikembangkan oleh Alexander Osterwalder dan Yves Pigneur, yang memetakan 9 elemen kotak yakni: customer segment, value proposition, channel, customer relationship, revenue stream, key resourcess, key activities, key partnership dan cost structure (Osterwalder and Pigneur, 2010).

$\mathrm{BMC}$ adalah alat yang digunakan untuk mendeskripsikan, menganalisa dan merancang model bisnis. Business Model Canvas juga diartikan sebagai bahasa yang sama untuk memvisualisasikan, menilai dan mengubah model bisnis; b) pelatihan manajemen permodalan bagi usaha mikro dan simulasi pembuatan proposal pengajuan kredit bank. Pelatihan ini menggunakan modul yang dipandu oleh Dr. Saiful Hurri, SP., M.Si. (Ketua PKM), dimana pemilik usaha dilatih bagaimana membuat proposal kredit dan 
proses pengajuannya ke bank serta syarat-syarat yang harus dipenuhi sebagai kelengkapan administrasinya. Sedangkan untuk pelatihan teknis penggunaan e-marketing oleh Nursayuti, SP., M.Si (anggota PKM); dan 3) tahap evaluasi PKM, yaitu pelaksanaan kegiatan evaluasi melihat apa saja kendala dan masalah yang muncul di lapangan. Lalu, dilakukan evaluasi jika ada kendala dan masalah untuk selanjutnya dicari solusi agar kegiatan tetap berlangsung dengan baik sesuai harapan.

\section{HASIL DAN PEMBAHASAN}

Mekanisme sosialisasi terhadap mitra dilaksanakan pada tanggal 15 November 2020. Adapun dalam kegiatan sosialisasi juga disusun jadwal pelaksanaan setiap tahapan PKM terhadap mitra. Pelatihan pembuatan manajemen permodalan, strategi pemasaran dilaksanakan tanggal 30 November 2020 yang dipandu oleh ketua dan anggota pengabdian. Mitra dilatih menggunaan e-marketing, mulai dari mempromosikan berbagai jenis produk Bolu Bhoi, merespon pesanan konsumen dan meng-update informasi (informasi pelayanan, menambahkan foto-foto di galeri, informasi ketersediaan stok Bolu Bhoi, membuat FAQ dan lainnya. Selanjutnya, mitra diberikan penjelasan terkait manajemen permodalan, diberikan pengetahuan mengenai pencatatan transaksi keuangan dalam jurnal dengan menempatkan mana akun yang di debet maupun yang di kredit. Mitra juga diberikan pengetahuan dan keterampilan menyajikan laporan keuangan laba/rugi usaha.

Pelatihan ini telah memberikan perubahan kepada pemilik usaha dengan mulainya mitra menggunakan buku khusus untuk mencatat seluruh transaksi keuangan usaha. Mitra telah dapat mengisi proposal pengajuan kredit bank yang biasanya terdiri dari latar belakang perusahaan berdiri, pengalaman perusahaan dalam usahanya, target market, bahan baku dan cara mendapatkannya, omset perbulan yang diakumulasikan pertahun dan mencantumkan laporan keuangan. Pendampingan tetap dilakukan untuk memonitoring agar keterampilan akuntansi tersebut tetap dilakukan dalam rangka perbaikan manajemen mitra pada usaha Bolu Bhoi di Desa Lancok-Lancok Kecamatan Kuala Kabupaten Bireuen. 

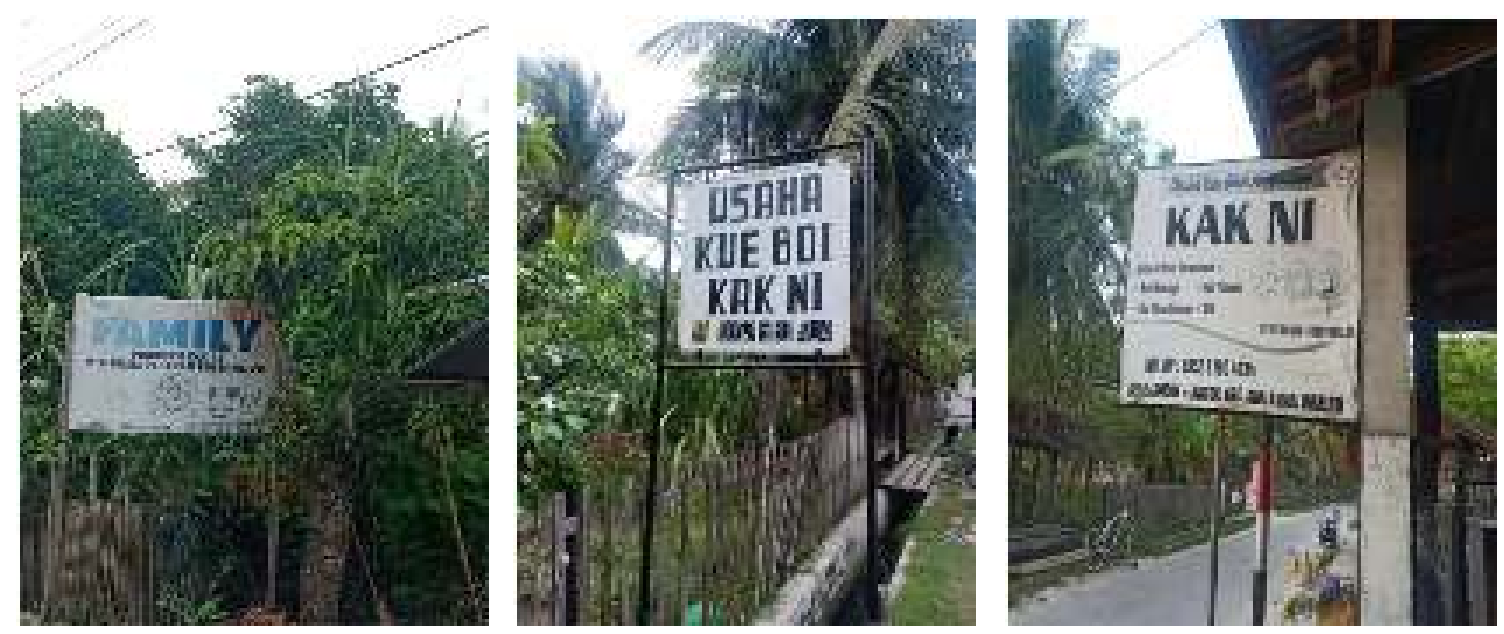

\section{KESIMPULAN DAN SARAN}

Kegiatan PKM ini telah memberikan kemampuan keterampilan pada Usaha Bolu Bhoi di Desa Lancok-Lancok Kabupaten Bireuen untuk melakukan pencatatan transaksi keuangan dan penyajian laporan keuangan usaha secara rapi, benar dan kontinyu, peningkatan omset usaha lebih dari sebelumnya sehingga menjadi 75\%. Peningkatan pengetahuan mengenai permodalan usaha/kredit bank pada mitra yakni pemahaman dalam pembuatan proposal kredit bank sebesar 70\%. Berdasarkan capaian hasil kegiatan PKM, maka disarankan untuk Pemilik Usaha Bolu Bhoi tetap rutin mencatat dan menggunakan pelaporan keuangan sebagai dasar pengambilan keputusan bisnis. Selain itu, implementasi kemampuan dalam pembuatan proposal kredit agar mendapatkan bantuan kredit bank dalam rangka meningkatkan modal guna memperluas sebuah usaha.

\section{UCAPAN TERIMA KASIH}

Ucapan terima kasih disampaikan kepada Lembaga Penelitian dan Pengabdian Masyarakat Universitas Almuslim yang telah memberikan dukungan moril maupun materiil terhadap terselenggaranya pengabdian masyarakat ini. Selanjutnya, ucapan terima kasih juga disampaikan kepada seluruh jajaran perangkat Desa Lancok-Lancok Kecamatan Kuala Kabupaten Bireuen yang telah memberikan kesempatan dan keluangan untuk menerima tim pengabdian masyarakat. 


\section{REFERENSI}

Assauri, S. 2013. Manajemen Pemasaran. Jakarta: Rajawali Pers.

Ayu, D., Dewi, L. 2017. Usaha Pada UMKM Genteng dan Batu Bata di Kabupaten Rembang. 1(1), 34-42.

Ching, Hong, Y., Fauvel, C. 2013. Criticisms, variation and experiences with business model canvas. International Journal of Small Business and Entrepreneurship Research. 1(4), 18-29.

Suryana. 2001. Kewirausahaan. Jakarta: Salemba Empat.

Wibowo, D. H., Arifin, Z., Sunarti. 2015. Analisis Strategi Pemasaran untuk Meningkatkan Daya Saing UMKM (Studi pada Batik Diajeng Solo). Jurnal Administrasi Bisnis (JAB), 29(1). administrasibisnis.studentjournal.ub.ac.i d.

Leiwakabessy, P., Lahallo, F. F. 2018. Pembiayaan Usaha Mikro Kecil dan Menengah (UMKM) Sebagai Solusi dalam Meningkatkan Produktivitas Usaha Pada UMKM Kabupaten Sorong. J-DEPACE (Journal of Dedication to Papua Community), 1(1), 11-21.

Hapsari, Denny Putri; Andari; Nahdiatul, A. H. 2017. Model Pembukuan Sederhana Bagi Usaha Mikro di Kecamatan Kramatwatu Kabupaten Serang. Jurnal Akuntansi, 4(2), 36-47.

Divianto., Febrianty. 2017. Pengaruh Pemahaman Pelaku UKM dalam Menyusun Laporan Keuangan terhadap Implementasi Laporan Keuangan Berdasar SAK ETAP dengan Persepsi Pelaku UKM sebagai Moderating Variable. International Journal of Social Science and Business, 1(3), 166-176.

Produktifitas kegiatan UMKM dalam Memanfaatkan Peluang Fasilitas Kredit Bank, dengan Memaksimalkan Kredit Usaha Kecil yang Merupakan Solusi dalam Permasalahan Pembiayaan UMKM. 